\title{
Late, but Before Schedule-A Bigeminal Rhythm with Blocked Premature Junctional Beats
}

\author{
Daniel Manna1 ${ }^{1}$, Thomas Lindow ${ }^{1,2 *}$ and Olle Pahlm ${ }^{2}$ \\ ${ }^{1}$ Department of Clinical Physiology, Växjö Central Hospital, Växjö, Sweden \\ ${ }^{2}$ Department of Clinical Sciences Lund, Lund University \& Clinical Physiology, Skåne University Hospital, Lund, Sweden
}

Submission: June 12, 2019; Published: July 05, 2019

*Corresponding author: Daniel Manna, Department of Clinical Physiology, Växjö Central Hospital, Växjö, Sweden

Abstract

Premature supraventricular ectopic beats are common findings in ambulatory ECG monitoring. Blocked ectopic beats may occur if the premature beat coincides with the refractory period of the downstream conductive tissues. We report of an uncommon, symptomatic bigeminal rhythm which resulted in an abrupt decrease of the heart rate because of blocked P waves. The blocked P waves appeared uncommonly late in the cardiac cycle because of a very His-near activation site. For anatomic reasons treatment was difficult and the patient received a pacemaker.

Keywords: ECG; Blocked extrasystoles; Bradycardia; Ambulatory ECG monitoring

Abbreviations: PJCs: Premature Junctional Contractions; PACs: Premature Atrial Contractions; EPS: Electrophysiological Study

\section{Learning Objective}

Blocked premature junctional or atrial beats can result in symptomatic bradycardia. A blocked P wave beyond the refractory period of the ventricular conduction tissue may suggest an AVnodal or His-near activation site.

\section{Background}

Premature supraventricular ectopic beats are common findings in ambulatory ECG monitoring. Blocked ectopic beats occur when the premature beat appears during the refractory period of the downstream conductive tissues. We describe a rarely occurring bigeminal rhythm which resulted in an abrupt decrease of the heart rate because of blocked $P$ waves, which appeared late in the cardiac cycle, but were still not conducted.

\section{Case Presentation}

A 63-year old lady was referred for ambulatory ECG monitoring by her general practitioner. She had no history of cardiac disease but since several months she was experiencing palpitations. A beta blocking agent had been tried but was discontinued due to symptomatic bradycardia. Lately she had also experienced dizziness, in addition to palpitations, especially at rest. Most of her symptoms were alleviated during light exercise such as walking.

\section{ECG analysis}

Resting ECG at the time of ambulatory ECG monitoring was normal. The 48-hour ambulatory ECG recording showed a large number of supraventricular $(\sim 17 \%)$ and ventricular $(\sim 5 \%)$ extrasystoles. Most of the supraventricular extrasystoles had similar P-wave morphology, suggesting a single origin. At night and during rest, multiple episodes ( 15 seconds each) of decreased heart rate were noticed, with sudden changes from $\sim 70 /$ min to $\sim 40 / \mathrm{min}$. During these episodes, a normal sinus beat, conducted to the ventricle with a positive $\mathrm{P}$ wave (Figure 1), was followed by a non-conducted negative $\mathrm{P}$ wave. The negative $\mathrm{P}$ waves appeared about $140 \mathrm{~ms}$ from the end of the $\mathrm{T}$ wave and a distinct, low-amplitude, positive Ta wave was noted.

\section{Discussion}

The bradyarrythmia was interpreted as blocked premature junctional contractions (PJCs) in bigeminy. Premature atrial contractions (PACs) are common and sometimes the premature atrial beat is not conducted through the $\mathrm{AV}$ node, giving rise to a blocked PAC [1,2]. This is most often due to the prematurity of the beat and not to a "diseased" AV node, i.e. the ventricular conduction system is still refractory [2]. Blocked PACs can be mis-interpreted as second-degree AV block [3]. In our case, the morphology of the non-conducted $\mathrm{P}$ wave was very different from that of the sinus $\mathrm{P}$ wave, and the risk of misinterpreting it as second-degree AV block was therefore minimal. The negative $\mathrm{P}$ wave was however, surprisingly late in relation to the refractory period of the preceding beat. Conduction to the ventricles was not possible due to a refractory distal conduction system, whereas 
retrograde depolarization of the atria was possible (the negative $\mathrm{P}$ wave). A premature beat with similar, negative $P$ wave morphology (Figure 2), recorded when the patient was active and the heart rate was higher, showed slightly longer time from the start of QRS to the end of the negative P wave (190ms) than the PR interval of the preceding sinus beat $(180 \mathrm{~ms})$, i.e. the conduction delay of the $\mathrm{AV}$ node was at least as long in the retrograde direction as in the anterograde direction. This suggests that the origin of the impulse was located either in the AV node or within the AV bundle. PJCs were common during the recording, but the pattern of blocked PJCs in bigeminy only appeared at rest with heart rates below $75 / \mathrm{min}$, likely due to increased refractory periods of the ventricular conduction system, which can increase with increased cycle length of the preceding beat [4]. During exercise, blocked PJCs where uncommon and her symptoms were relieved.

Figure 1: Blocked junctional extrasystoles.

Ambulatory ECG recording at $25 \mathrm{~mm} / \mathrm{s}, 10 \mathrm{~mm} / \mathrm{mV}$, showing blocked junctional extrasystoles. All QRS complexes are preceded by a positive $\mathrm{P}$ wave. The $\mathrm{T}$ waves are followed by premature, non-conducted negative $\mathrm{P}$ waves. Note the positive Ta wave reflecting atrial repolarization (arrow). A laddergram, below the ECG strip, shows the origin of the impulse (black dot) and impulse propagation (black lines). An interrupted black line denotes blocked conduction. A denotes atrial conduction, AVN denotes AV-nodal conduction and $\mathrm{V}$ ventricular conduction.

Figure 2: Conducted junctional extrasystole.

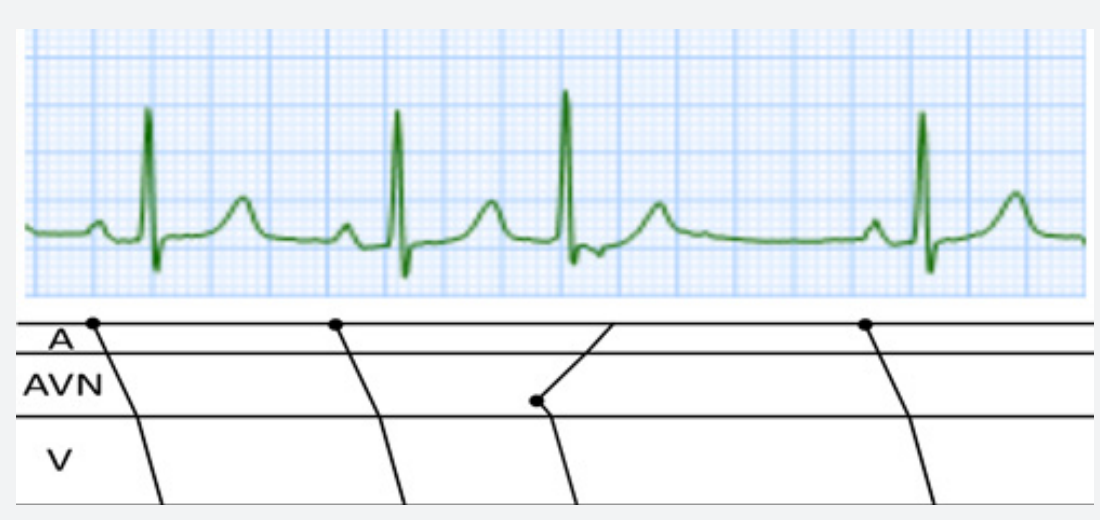

Ambulatory ECG recording at $25 \mathrm{~mm} / \mathrm{s}, 10 \mathrm{~mm} / \mathrm{mV}$. A normal sinus beat is followed by a premature narrow QRS complex followed by a negative $\mathrm{P}$ wave - a conducted junctional extrasystole. The PR interval of the sinus beats was slightly shorter than the time from start of QRS to the end of the negative $P$, which means that the conduction delay is at least as long in the retrograde direction as in the anterograde direction. This suggests that the origin of the impulse is located close to the His bundle. A laddergram, below the ECG strip shows the origin of the impulse (black dot) and impulse propagation (black lines). A denotes atrial conduction, AVN denotes AV-nodal conduction and $\checkmark$ ventricular conduction.

A treatment attempt with flecainide was terminated due to adverse reactions. The interpretation from the surface ECG of blocked PJCs was later confirmed by an electrophysiological study (EPS). During EPS, supraventricular ectopic beats were seen, and they could be suppressed by isoprenaline but re-appeared when isoprenaline infusion was stopped. The earliest endocardial activation site was located above the coronary sinus ostium, very close to the bundle of His. After EPS the patient was in complete AV block. A pacemaker was implanted. On follow-up 3 month later, she had had no symptomatic episodes.

\section{Conclusion}

Blocked premature junctional or atrial beats can result in symptomatic bradycardia. In this case, an unexpectedly late, 
blocked supraventricular ectopy could be explained by a very Hisnear activation site, which made treatment difficult.

\section{References}

1. Alper A, Gungor B, Turkkan C, Tekkesin A (2013) Symptomatic bradycardia caused by premature atrial contractions originating from right atrial appendage. Indian Pacing Electrophysiol J 13(3): 114-117.

2. Wagner GS, Marriott HJL (2008) editors. Marriott's practical electrocardiography. 11. ed. Philadelphia, Pa.: Wolters Kluwer Health/Lippincott Williams \& Wilkins, USA, pp. 293-346.
3. Gaudio C, Di Michele S, Ferri FM, Mirabelli F, Franchitto S, et al. (2004) A case of non-conducted atrial bigeminy simulating a second-degree atrioventricular block. A holter ECG diagnosis. Eur Rev Med Pharmacol Sci 8(4): 169-171.

4. Denes P, Wu D, Dhingra R, Pietras RJ, Rosen KM (1974) The effects of cycle length on cardiac refractory periods in man. Circulation 49(1): $32-41$.

\begin{tabular}{l} 
Your next submission with Juniper Publishers \\
will reach you the below assets \\
- Quality Editorial service \\
- Swift Peer Review \\
- Reprints availability \\
- E-prints Service \\
- Manuscript Podcast for convenient understanding \\
- Global attainment for your research \\
- Manuscript accessibility in different formats \\
( Pdf, E-pub, Full Text, Audio) \\
- Unceasing customer service \\
Track the below URL for one-step submission \\
https://juniperpublishers.com/online-submission.php \\
\hline
\end{tabular}

